\title{
Agricultural meal docking service based on the electronic commerce
}

\author{
platform \\ Li Guo *, Shuangshuang Su, Danni Hao, Hao Shen \\ School of Economy and Management, Tianjin Agricultural University, China \\ *Corresponding author: Li Guo, Logistics Management, 15822088032, 942252975@qq.com
}

\begin{abstract}
There are some problems in traditional agricultural products circulation channels, including too many links, exorbitant cost and huge loss, which can't adapt to the developing of modern agriculture and related industries. In recent years, with the development of the work about “Agricultural Meal Docking”, it has a positive influence on agricultural production base and catering enterprises. Based on the analysis about the current situation of "Agricultural Meal Docking” in our country, the paper proposes the "Agricultural Meal Docking” model based on electronic commerce platform, analyzes its characteristics and puts forward some suggestions on the development of “Agricultural Meal Docking” electronic commerce.
\end{abstract}

Keywords: agricultural meal docking; electronic commerce; model; logistics system

\section{Introduction}

As the first industry of our country, agriculture plays an irreplaceable role in the basic of life, which is the premise of other industry production and development. ${ }^{1}$ Agricultural products enter into the catering industry through traditional channels, and generally go through one or more lengthy supply chains, such as the wholesale markets of agricultural products, retail public markets, catering enterprises, consumers etc.It has caused too much circulation and exorbitant cost.

According to the statistics, there are nearly 500 catering enterprises in China. Catering industry is a huge traditional industry, but it purchase agricultural products by e-commerce platform rarely. A contradiction between "small-scale production" of farm and sideline products and "big-market" of catering enterprises have been seriously impeding the pace of agricultural modernization and the sustainable and healthy development of catering enterprises in our country. "Agricultural Meal Docking”, the new agricultural product circulation pattern, which could help to solve this contradiction. ${ }^{2}$

As a new agricultural product circulation way, "agricultural meal docking" has received 
extensive attention at domestic and abroad. Related research have suggested a variety of patterns for "Agricultural Meal Docking”, including "Farmers + Specialized Agricultural Enterprises + Catering Enterprises", "Farmers + Agricultural Cooperatives + Catering Enterprises", "Farmers + Farm + Catering Enterprises" etc. Based on the relevant academic researches, we have put forward the theory of model of “Agricultural Meal Docking”which based on electronic commerce platform.

\section{The research on the pattern of "Agricultural Meal Docking”}

Traditional circulation of agricultural products goes through many links, including the agricultural production base, the wholesale market, and the farmers' market, and catering enterprises, etc, which not only have a strong impact on the freshness of agricultural products, but also increase costs of circulation and storage incurred by intermediate processes as well as material costs of the catering industry. "Agricultural Meal Docking” is a new way. It means that catering enterprises buy products directly from the agricultural production base in various ways in order to reduce the participation of the middlemen, cut costs and achieve direct cooperation between catering enterprises and agricultural producers. ${ }^{3}$

The "Agricultural Meal Docking” model is based on electronic commerce platform that has established a whole e-commerce industrial chain from agricultural production base to catering enterprises. It can achieve rapid and efficient docking between production bases and catering enterprises according to a series of functions on the e-commerce platform, encompassing the ordering system, logistics system and data analysis system, etc. The theoretical model is shown in fig. 1.

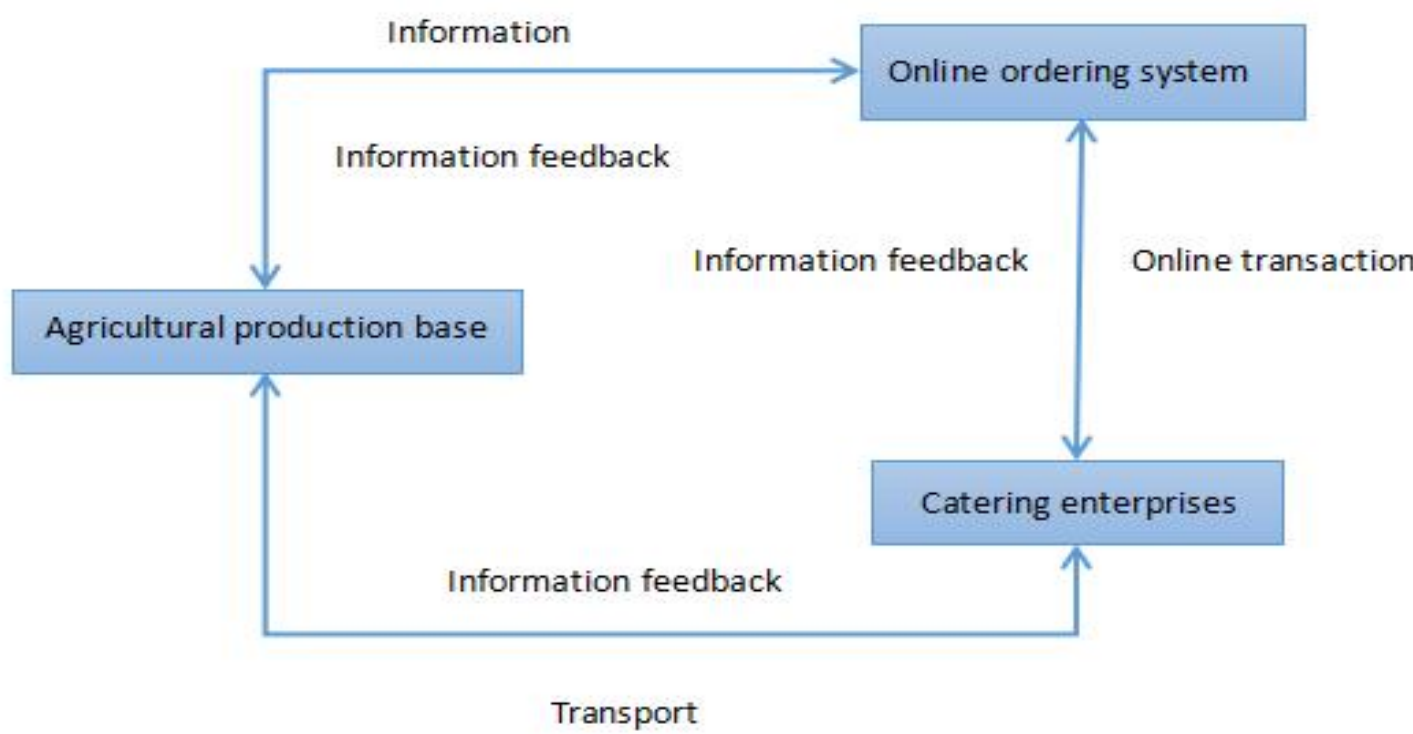

Fig. 1 - "Agricultural Meal Docking” model

According to the new "Agricultural Meal Docking” model, catering enterprises purchase an agricultural product on the e-commerce platform. The "Agricultural Meal Docking” is a new model of the circulation of agricultural products. It realizes the docking of catering enterprises 
and farmers, small production and large markets, sales data analysis and production guidance. For simple docking between catering enterprises and farmers, there is a problem of imperfect service system, which restricts the docking of catering enterprises and farmers and hinders the spread and development of "Agricultural Meal Docking”.

The "Agricultural Meal Docking” model which is based on the e-commerce platform delivers services to farmers and catering enterprises to create a better docking platform and development environment. There are three characteristics of "Agricultural Meal Docking” services:

(1) Make to order

The company's lump-sum sale of agricultural products and catering enterprises' demand together make a data analysis and provide data for farmers. Because of the foreseeable production, farmers avoid the blindness of production. The service enterprises have a powerful information analysis system that predicts customer demand properly according to the sales data and feedback information from the market, which is necessary to farmers.

Because of blind production, there are a lot of farmers causing huge losses every year. In order to avoid the supply shortage of agricultural products, enterprises provide the analysis data for farmers. Therefore, the service enterprises and farmers achieve a win-win situation.

(2) Expand market share

Because of catering enterprises' large-scale consumption on the platform, online transaction pathway has accumulated many longtime customers. At the same time, it provides reliable customers to farmers. Online transaction pathways push agricultural products directly to the catering enterprises, avoiding the agricultural products from going through the wholesale market, thus guaranteeing the freshness of agricultural products. Farmers' customers form agricultural stockists into catering enterprises. After tapping the customer market online, the platform could harvest reliable customers.

(3) Reduce circulation

The enterprises could help the base transport agricultural products directly enter into catering enterprises, thereby reducing the circulation of wholesale markets and retail market. In general, agricultural products go through the production base and wholesale markets, retail markets, catering enterprises. In the traditional circulation, too much circulation causes a waste of time.

More seriously, the agricultural products lose freshness and that could make the prices of agricultural products continue to decline. The platform replaces the process of farmers to catering business, and puts agricultural production from farmers directly to the catering enterprises. It could ensure the freshness and price of agricultural products. 


\section{Popularization and development suggestions for the "Agricultural Meal Docking" model}

\subsection{Strengthening the construction of the basic ability in "Agricultural Meal Docking” e-commerce}

There are lots of phenomenon in China. for instance, the agricultural company informatization level is lower, the information of the network is not popular; the number of the agricultural e-commerce websites are limited, and online trading function is not complete; Internal management informatization is serious insufficient. Most of our agricultural enterprises of the network to be understood, acceptant and application of ability are not high by itself; the concept of the utilizable network business are unclear, modern management ideas, method and technology of consciousness are lack, Electronic commerce constructions have large investment, long period, the large amount of maintenance. ${ }^{4}$

We need to do a lot to strengthen the construction of the basic ability in "Agricultural Meal Docking” e-commerce.

Firstly, improve the construction of “Agricultural Meal Docking”information platform. The construction focus of “Agricultural Meal Docking”based on e-commerce is to build an information platform, to achieve timely and accurate information docking between farmers, “Agricultural Meal Docking”service enterprises and catering enterprises.

Secondly, we should regularly make awareness and technical training of "Agricultural Meal Docking”for farmers and catering enterprises, which focus on large-scale farm operators, cooperatives leaders, large catering business leaders, so that they really understand the advantages and prospects of "Agricultural Meal Docking”in modern society, improving their e-commerce awareness of "Agricultural Meal Docking”, mobilizing them to carry out the “Agricultural Meal Docking” work, speeding up the development process of “Agricultural Meal Docking”.

\subsection{Accelerating the development of agricultural products cold chain logistics}

Logistics transformation is essential to the process of the promotion of "Agricultural Meal Docking”. According to the development of logistics in China, we should strive to develop agricultural cold chain logistics, and cultivate cold chain logistics leading enterprises actively. Continuously improve the level of transport infrastructure, strengthen the production, storage, processing, transportation, sales of all nodes of technological transformation and upgrading, and lump them together to build a professional cold chain logistics operation system. ${ }^{5}$

The government should increase the support for infrastructural construction about agricultural product transformation, improve the level of transport conditions and conveyance for agricultural production, and encourage the transformation of cold chain transportation technology and purchase advanced refrigerated equipment to ensure the quality and safety of “Agricultural Meal Docking”. 


\subsection{Cultivating and developing new agricultural management subject}

Developing new agricultural management is an important starting point for the construction of modern agriculture. It's also a key for the development of “Agricultural Meal Docking”. At present, there are still many problems in the popularization of “Agricultural Meal Docking” model. Among them, the small scale of production and lack of professional skills are the important factors that restrict the popularization of “Agricultural Meal Docking”.

Specialization and scale of production for agriculture could provide a stable and safe source of food for catering enterprises, and promote the popularization of "Agricultural Meal Docking” model. Therefore, we should strive to develop rural cooperatives, family farms, agricultural enterprises and other different types of new types of agricultural management.

For that, it not only improves the market position of farmers and increases farmers' income, but also promotes the development of catering enterprises. In the near future, using “Agricultural Meal Docking” pathway as sharing platform, based on modern information,and using modern information technology makes agriculture e-commerce will be the most convenient way among the public.$^{6-7}$

\section{Conclusions}

“Agricultural Meal Docking” model based on the electronic commerce platform through MTO can promote online business, reduce the circulation of agricultural products, and weaken the drawbacks of traditional agricultural products circulation, thus realizing rapid and efficient docking between the production base and catering enterprises. It plays an indispensable role in the development of the circulation of agricultural products in China, and it is also an inevitable trend of the rapid development of e-commerce.

\section{Acknowledgements}

This research was supported by the innovation and entrepreneurship training program for college students in Tianjin(Project No:201510061029), China.

\section{References}

1. B. Q. Hu, A Study of New Agricultural Circulation Model-On the Basis of “Agriculture meal docking” Model, J. Modern Economic Information. 12 (2015) 352.

2. P. F. Wang, C. X. Chen, M. Y. Huang, "Agriculture Meal Docking” Circulatory Model, J. The Commercial Promotion and Reasons of Development Theoretical Exploration. 1 (2013) 56-64.

3. X. Q. Fu, Z. Y. Chen, The Study of Solution of Retail Online and Traditional Retail Model, J. Management and Administration. 14 (2010) 36-37. 
4. J. Kuang, L. Cai, H. C. Li, The Development Model Electronic Commerce of Regional Agriculture, J. IFIP Advances information and Communication Technology 317. 9 (2009) 260-267.

5. H. Y. Jiang, S. S. Yuan, L. W. Pang, A Study of New “Agriculture Meal Docking” Model, J. Rural Management. 119 (2013) 44.

6. K. Y. Kuan, P. Y. K. Chau, A Perception-Based Model for EDI Adoption in Small Business Using a Technology Organization Environment Framework, J. Information\&Management. 38 (2001) 507-521.

7. K. L. Kraemer, J. Dedrick, Strategic Use of Internet and E-commerce, J. Cisco System. Joural of strategic information system. 11 (2002) 5-29. 